\title{
Granulomatous giant cell reticulosis associated with cases of treated leukaemia
}

\author{
G. KRASZNAI, S. KERESZTURY, AND L. SZƯCS \\ From the Department of Pathology, University Medical School, Debrecen, and the Pathological \\ Department of Semmelweis' Hospital, Miskolc, Hungary
}

SYNOPSIS Focal granulomatous giant cell reticulosis was observed in lymph nodes from treated cases of chronic lymphatic and chronic myeloid leukaemia. On the basis of clinical behaviour and histological appearance, it seems plausible that in the terminal phase of leukaemia non-neoplastic reactive reticulosis developed very similar in appearance to lymphogranulomatosis. The possible relationship between malignant lymph node tumours, Hodgkin's disease, and leukaemia is discussed. Repeated biopsies from leukaemic patients would perhaps permit of further clarification of this process.

Reticulosis and reticulosarcoma associated with leukaemia have been dealt with in a number of publications during recent decades. In 1928 Richter observed the coexistence of regional reticulosarcoma and lymphatic leukaemia. Tumour-like hyperplasia of the reticulo-endothelial system with leukaemia was described in 1932 by Loesch. Similar observations have been reported concerning myeloid leukaemia (Introzzi, 1955; Belolipetskia and Gets, 1960; Lüscher, 1960; Garbsch, Peschl, Reimer, Simon, and Zeitlhofer, 1963). Some authors postulated a direct casual relationship between cytostatic therapy and tumour-like reticulosis (Chiari, 1964; Fritsch, 1964).

In our cases granulomatous giant cell reticulosis similar in appearance to Hodgkin's disease was found in lymph nodes infiltrated by leukaemic cells.

\section{REPORTS}

CASE 1 L.J., a man aged 51 years, was diagnosed as a case of lymphatic leukaemia in 1962. The leucocyte was 28,000 per $\mathrm{mm}^{3}$. From then on the patient was admitted to hospital at short intervals because of cutaneous leukaemic manifestations. In 1963 he received Degranol ${ }^{1}$ and ${ }^{32} \mathrm{P}$ therapy. Radiotherapy, consisting of $2,800 \mathrm{r}$ to the enlarged lymph nodes, was employed in 1964 . At that time the leucocyte count was 37,000 per $\mathrm{mm}^{3}$. Treatment followed with prednisolone, Degranol $(500 \mathrm{mg}$.), and ${ }^{32} \mathrm{P}(1,000 \mu \mathrm{c}$.). The leucocyte count rose gradually $\left(37,000-85,000\right.$ per $\left.\mathrm{mm}^{3}\right)$. A peripheral smear showed $2 \%$ bands, $8 \%$ segmented neutrophils, $2 \%$ eosinophils, $82 \%$ lymphocytes, and $6 \%$ disrupted lymphocytes.

${ }^{1}$ Degranol, BCM: 1, 6-bis (beta-chlorethylamin)-1, 6-desoxi-D-mannit2 HCl, Chinoin, Budapest.

Received for publication 19 April 1967.
The patient died two years after the first admission in 1964.

The following is an extract from the necropsy report (Dote 256/64). Gross findings correspond to lymphatic leukaemia. Generalized lymph node enlargement, hepatosplenomegaly, and secondary anaemia were evident.

Histological findings The normal architecture of the cervical, supraclavicular, and axillary lymph nodes is lost. The nodes are infiltrated by leukaemic cells and, in addition, polymorphic reticulum cell proliferation is seen in large foci (Fig. 1), which are characterized by reticulum cells with pale nuclei (some with pyknotic ones), 'mirror image' cells (Fig. 2), multinucleated cells with an average size of $40 \mu$ resembling those of ReedSternberg type (Fig. 3). The giant cells contain three to five nuclei, their nucleoli are prominent and basophilic, their plasma is finely granulated or homogenously acidophilic, and on staining with Sudan III exhibit lipid storage of fine droplet type. The granulomatous foci are circumscribed, within them necrobiotic, necrotic cells, and mitotic figures are detectable; leukaemic cells are scanty. The reticular framework is destroyed. Collagenous fibrils tend to proliferate around the blood vessels.

The diagnosis is chronic lymphatic leukaemia, with lymphogranulomatosis-like focal granulomatous giant cell reticulosis in the cervical, supraclavicular, and axillary lymph nodes.

CASE 2. M.N.J., a woman aged 63 years, was diagnosed as a case of myeloid leukaemia in 1961. The patient was often admitted to hospital where she received Myleran treatment. In January 1964, the leucocyte count was 150,000 per $\mathrm{mm}^{3}$ (the peripheral smear showed $13 \%$ juveniles, $12 \%$ bands, $41 \%$ segmented neutrophils, $2 \%$ eosinophils, $1 \%$ lymphocytes, $2 \%$ basophils, $21 \%$ 


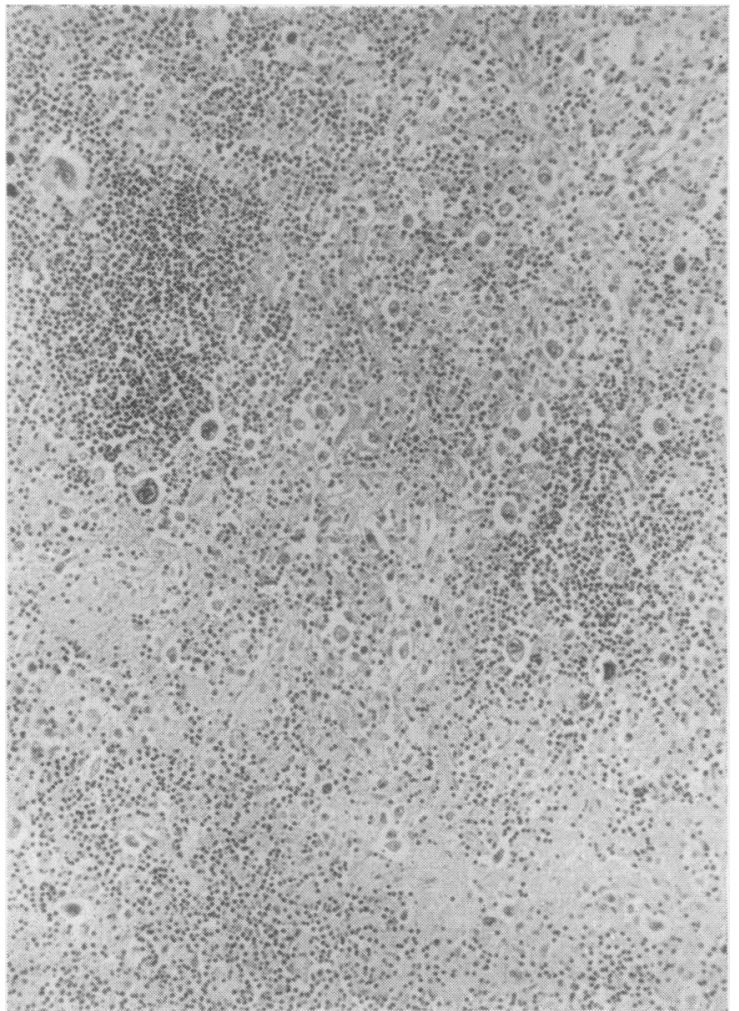

FIG. 1 .

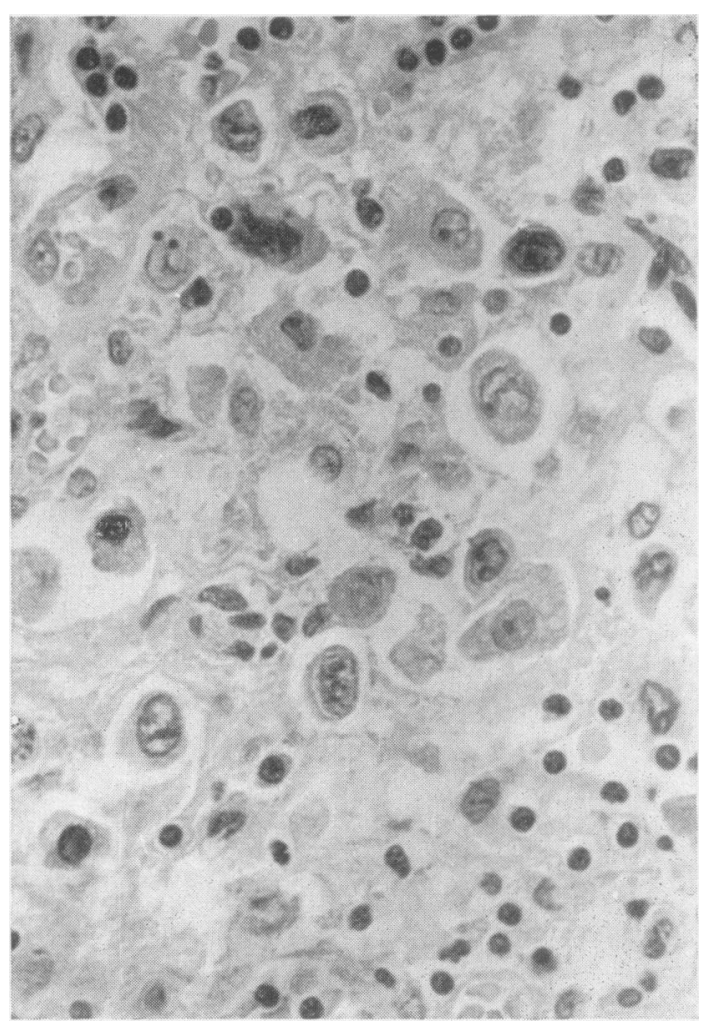

FIG. 2.

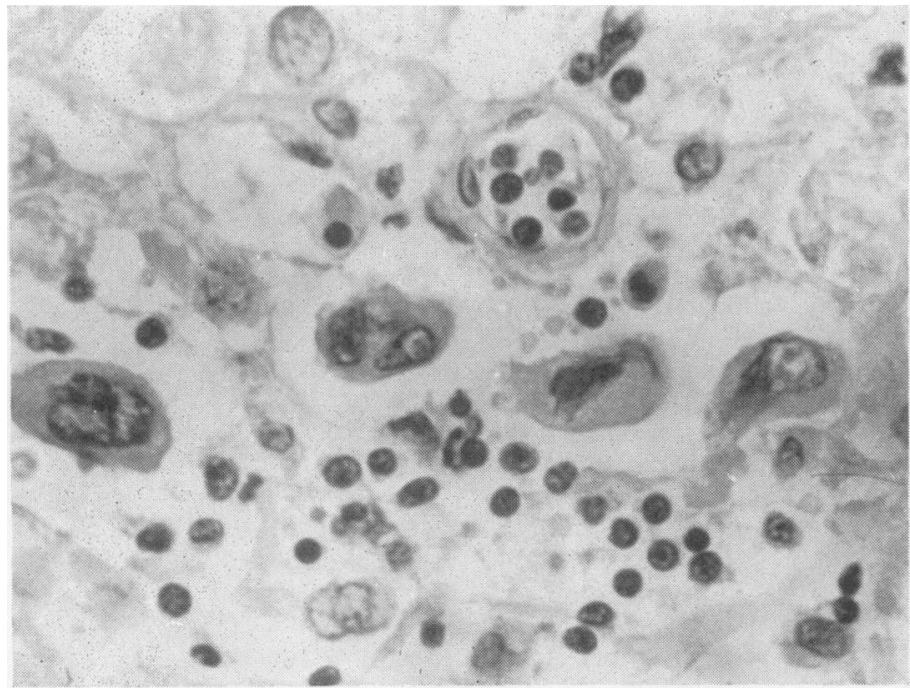

FIG. 3.
FIG. 1. Case 1: cervical lymph node. In addition to lymphoid leukaemic infiltration polymorphic reticulum cell proliferation is present in large granulomatous foci. Haematoxylin and eosin, $\times 100$.

FIG. 2. Case 1: cervical lymph node. Irregularly shaped reticulum cells with pale or pyknotic nuclei are seen in granulomatous foci. Haematoxylin and eosin, $\times 400$.

FIG.3. Case 1: cervical lymph node. Giant cells imitating those of ReedSternberg type and 'mirror image' cells from foci seen in Figure 1. Haematoxylin and eosin, $\times 600$. 
myelocytes, and $8 \%$ myeloblasts). After two weeks of Myleran treatment remission followed. The patient was re-admitted in March 1964, when the leucocyte count was 37,000 per $\mathrm{mm}^{3}$. She died two days later.

The following is an extract from the necropsy report $(\mathrm{M} / 270 / 64)$. Gross findings were consistent with those of myeloid leukaemia. General lymph node enlargement and hepatosplenomegaly were prominent. In bones examined diffuse 'pyoid' marrow was found.

Histological findings The architecture of the inguinal, paraaortal, and pelvic lymph nodes has disappeared, and they are infiltrated by leukaemic cells. Focal granulomatous lesions rich in both cells and fibrils are seen (Fig. 4), and are made up of polymorphic reticulum cells, and cells closely related to those of the ReedSternberg type. The latter cells have abundant dark basophilic cytoplasm. The number of nuclei ranges from 3 to 5 , and they are connected by wide chromatin strands; their shape and size vary, irregular nuclear processes and pyknosis are frequently found, and the chromatin substance is homogeneous or consists of coarse granules (Figs. 5 and 6). Among the reticulum cells appear cells with very pale nuclei. Eosinophils and myeloid leukaemic cells are found only with difficulty in the foci.

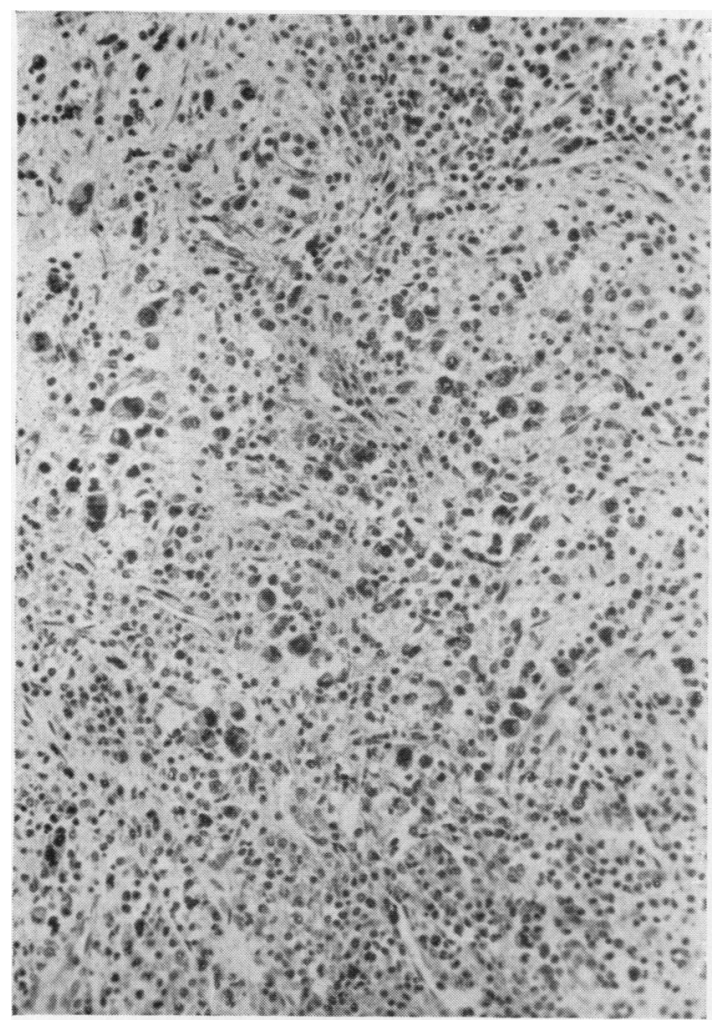

FIG. 4. Case 2: paraaortal lymph node. Polymorphic reticulum cell proliferation, pleomorphic nuclear structure, intense fibrosis. Haematoxylin and eosin, $\times 120$.

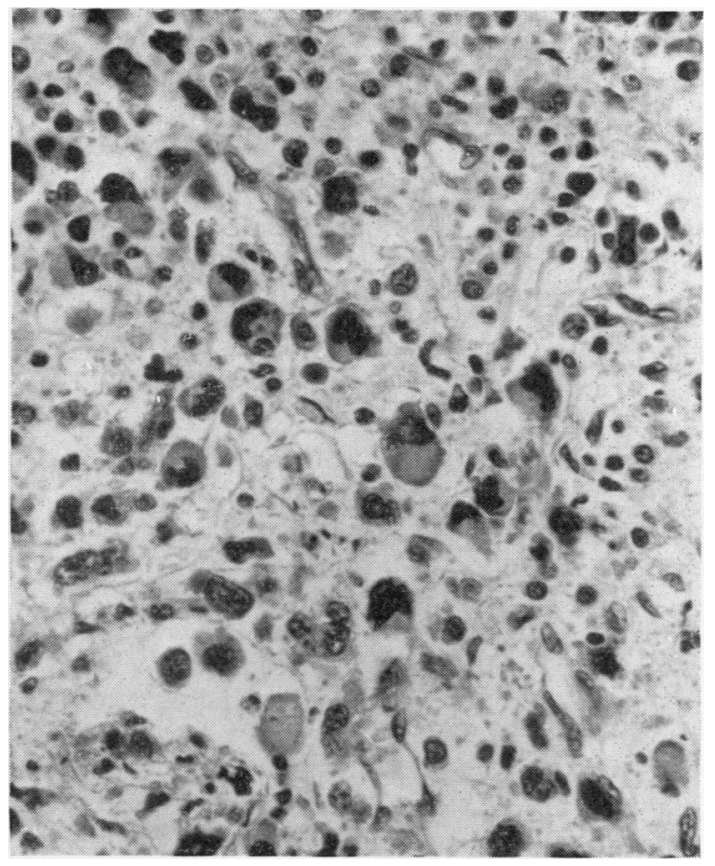

FIG. 5. Case 2: paraaortal lymph node. Pyknotic cells, giant cells, and eosinophils are visible. Haematoxylin and eosin, $\times 350$.

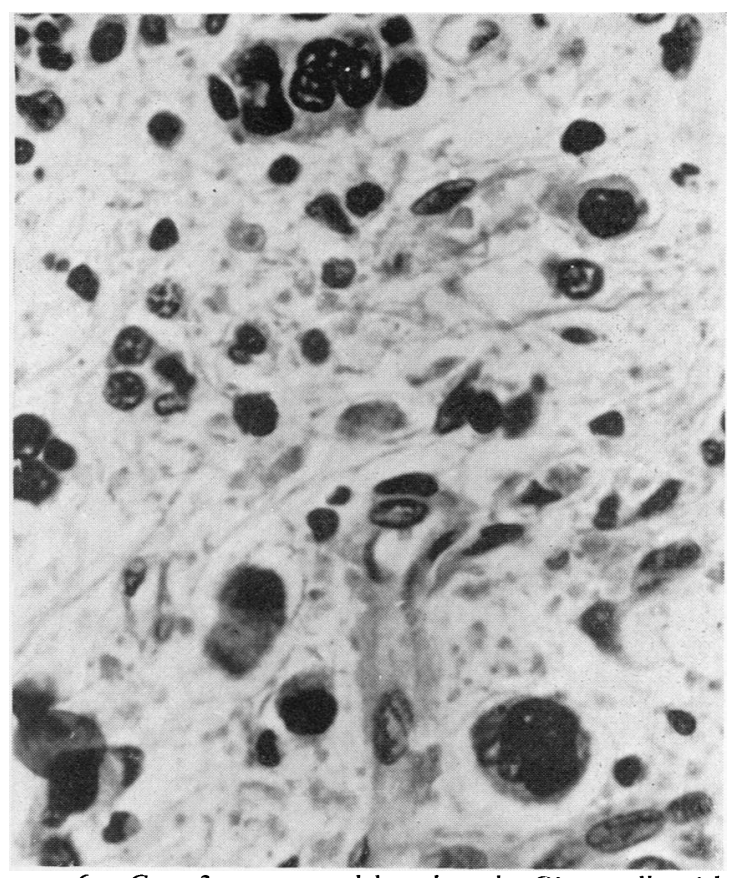

FIG. 6. Case 2: paraaortal lymph node. Giant cells with 3-5 dark basophilic nuclei similar in appearance to ReedSternberg cclls. Haematoxylin and eosin $\times 400$. 
The diagnosis is chronic myeloid leukaemia. In addition to leukaemic infiltration there is a focal giant cell reticulosis resembling lymphogranulomatosis in the inguinal, paraaortal, and pelvic lymph nodes.

\section{DISCUSSION}

The following four relationships may exist between lymph node tumours and the leukaemias. (1) The leukaemic phase occurs in the course of malignant neoplastic lymph node diseases, and is represented either by lymphoid leukaemic transformation of lymphosarcoma or by a histiocyte-leukaemic change in reticulosarcoma. (2) Malignant lymph node tumour and leukaemia exist simultaneously. The coexistence of Hodgkin's disease and leukaemia also belongs to this category (Seife, Reich, and Lisa, 1951; Krim, Meyer, Rosenthal, and Ritz, 1952; Samwick, Cohn, and Swiller, 1955; Epstein, 1956; Keiser, Uehlinger, and Virieux, 1961; Lacher and Sussman, 1963; Guichard, Vauzelle, and Roachet, 1964). (3) Leukaemia associated with reticulosarcoma forms the third group. (4) Leukaemia may be associated with a non-neoplastic reactive reticulosis. As a rule the diagnosis is established in this category by post-mortem examination. The transformation possibly develops in the final stage of leukaemia, which is why it is often referred to as terminal reticulosis, although its terminal occurrence has not been proved. Only the histological study of repeated lymph node biopsies could form a sufficient basis for a definite conclusion. But removal of lymph nodes from diagnosed leukaemic patients is not accepted as standard practice. Hence the terminal character of the transformation is doubtful.

The lesion is correlated with cytostatic therapy. Fritsch (1964) suggests that the cytostatics and $x$-ray treatment may exert a direct effect or an indirect effect upon the reticulo-endothelial system, i.e., substances from destroyed cells are responsible for the proliferation, or even that the reactive reticulosis is due to the prolonged disease process. In addition Fritsch postulates a common aetiological factor which affects the haemopoietic tissue and reticulo-endothelial system alike. In opposition to this view Chiari (1964) claims that the source of this peculiar cell proliferation is the haemocytoblasts.

Our cases can be fitted into the fourth group. The granulomatous giant cell proliferation affected the lymph nodes exclusively, and similar changes in the spleen, bone marrow, and liver were not

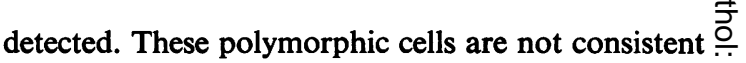
with degenerated leukaemic elements because $\vec{F}$ (1) phagocytosis, lipid storage, and mitotic activity are rarely seen in degenerated cells; (2) the foci are separated from the adjacent leukaemic cells.

The non-megakaryocyte origin of multinucleated cells is supported by their absence in the spleen. $\stackrel{\complement}{\complement}$ Also in our case of lymphatic leukaemia a considerable number of giant cells were observed, while $\vec{\circ}$ signs of myeloid metaplasia in the neighbourhood of multinucleated cells were lacking. Hence we do not $\vec{\omega}$ consider these mutinucleated cells megakaryocytes inherent in metaplastic erythromyelopoesis.

In both cases the histological picture resembles i Hodgkin's disease from many points of view. The $\dot{\sigma}$ focal granulomatous reticulum cell proliferation $\stackrel{\infty}{\oplus}$ was confined to the lymph nodes. The large reticulum cells resembled Hodgkin cells. 'Mirror image' 욱 cells, infiltration by eosinophils, necrosis, and fibrosis were present.

The histological picture also suggests two theoretical explanations. Conceivably the leukaemia and Hodgkin's disease coexisted as two separate diseases. $\stackrel{\Phi}{-}$ If so the possibility of a common aetiology and pathogenesis is logical, although such a connexion between the two pathological processes has not been substantiated by previous lymph node examinations.

The most plausible explanation is that a reactive non-neoplastic reticulosis, very similar in appearance to Hodgkin's disease, developed in the terminal phase of leukaemia due to cytostatic therapy.

Repeatedly performed lymph node biopsies in leukaemic cases would enable further clarification of this process.

\section{REFERENCES}

Belolipetskia, T. A., and Gets, I. I. (1960). Arkh. Pat., 22(3), 61. Chiari, H. (1964). Beitr. path. Anat., 130, 51.

Epstein, R. D. (1956). N.Y. St. J. Med., 56, 3518.

Fritsch, S. (1964). Zbl. allg. Path. path. Anat., 106, 172.

Garbsch, H., Peschl, L., Reimer, E. E., Simon, W., and Zeitlhofer, J. (1963). Wien. Z. inn. Med., 44, 205.

Guichard, A., Vauzelle, J. L., and Roachet, M. (1964). Arch. Anat. path., 12, 225.

Introzzi, P. (1955). Schweiz. med. Wschr., 85, 945.

Keiser, G., Uehlinger, E., and Virieux, C. (1961). Acta haemat. (Basel), 26, 29.

Krim, M., Meyer, L. M., Rosenthal, J., and Ritz, N. D. (1952). Arch. intern. Med., 89, 297.

Lacher, M. J., and Sussman, L. N. (1963). Ann intern. Med., 59, 369.

Loesch, J. (1932). Frankfurt. Z. Path., 44, 351.

Lüscher, M. (1960). Schweiz. med. Wschr., 90, 983.

Richter, M. N. (1928). Amer. J. Path., 4, 285.

Samwick, A. A., Cohn, H., and Swiller, A. I. (1955). Ann. intern. Med.,

43, 868.
Seife, M., Reich, C., and Lisa, J. R. (1951). Acta haemat. (Basel), 5, 65. 